\title{
Oil palm based cellulose esters as raw material for environmentally friendly bio-plastic
}

\author{
Tjahjono Herawan $^{1 *}$, Meta Rivani ${ }^{1}$, Halimatudahliana $^{2}$, Suryo $\operatorname{Irawan}^{3}$ \\ ${ }^{1}$ Indonesian Oil Palm Research Institute (IOPRI), J1. B. Katamso No. 51 Medan, \\ ${ }^{2}$ Chemical Engineering Department, North Sumatera University, Medan \\ ${ }^{3}$ Center for Chemical and Packaging, Indonesian Ministry of Industry, Pasar Rebo, Jakarta \\ ${ }^{*}$ Corresponding author Tel.: + 62617862477, Fax: +62617862488 \\ E-mail: tjherawan@yahoo.com
}

Received: 30 January 2018

Revised: 14 August 2018

Accepted: 17 August 2018

\begin{abstract}
Besides producing oil, oil palm also produces a huge amount of biomass such as empty fruit bunch. Both of those products had a big potential to be used as a source of plastic raw materials called bio-plastics. Bioplastic can be produced by reacting long-chain fatty acid with cellulose. The long-chain fatty acid source can be obtained from crude palm oil (palmitic acid and oleic acid) and palm kernel oil (lauric acid), while cellulose can be obtained from oil palm empty fruit bunch waste (OPEFB). Cellulose was produced from OPEFB by an alkaline process on a pilot plant scale. The yield of $\alpha$-cellulose obtained as much as $32-38 \%$ of the OPEFB processed. The cellulose ester was synthesized by esterification between cellulose of OPEFB and modified fatty acid from palm oil in a mild condition. Conversion of cellulose ester produced reached $92.7 \%$ with percent increase weight reach $460 \%$, degree substitution (DS) 2.21 and melting point at $201^{\circ} \mathrm{C}$. The tensile strength of the cellulose ester film was lower than the tensile strength of petroleum-based plastics (low density poly ethylene/LDPE), which averaged $73 \mathrm{~kg} / \mathrm{cm}^{2}$ versus $108 \mathrm{~kg} / \mathrm{cm}^{2}$, so it was necessary to add additives to increase tensile strength and elasticity properties.
\end{abstract}

Keywords: Bio-plastics, cellulose esters, empty fruit bunch, oil palm.

\section{INTRODUCTION}

Currently, the demand for plastic in Indonesia is very high, where the market share of $60 \%$ is dominated by food packaging and consumer goods industries. According to data released by the Indonesian Bureau of Statistics, Indonesia's plastic needs in 2013 reached 3.4 million tons, and then jumped to 4.6 million tons by the end of 2016. The installed capacity of the effective national plastic industry is about 3.5 million tons per year so that national plastic production is not sufficient for domestic plastic needs. Therefore, about 50\% of the plastic requirement is imported and the import figure is continuously increasing by $7-8 \%$ annually.

Cellulose began to be a concern as a natural raw material of polymer since its abundant availability in the world and is renewable. Naturally, cellulose has good mechanical properties and can be used directly as a filler or a reinforcement in material products. Hairani et al. (2015) have reported the effect of microcrystalline cellulose (MCC) from oil palm empty fruit bunch (OPEFB) loading on tensile strength properties of cassava starch composite. Their report shows that the tensile strength of the composite increase by adding up to $10 \%$ of MCC in the matrix. The same results have also been shown by Isroi et al. (2017) who reported the effect of cellulose from OPEFB on tensile strength, elastic modulus and elongation break of the bio-plastic cellulose-starch composite. Nevertheless, the elastic modulus and elongation break of its bio-plastic should be improved so that it resembles conventional and commercial plastic.

The structure of hydrogen bonds in cellulose is so complex that it is difficult for chemical compounds to react with cellulose, are hydrophobic and not soluble in general solvents. Some modifications must be made so that hydrogen bonds break so that the cellulose monomer unit is more accessible to chemical compounds. The modification process can also improve its plasticity. 
There are two modes of cellulose are homogeneous and heterogeneous. In a homogeneous modification, cellulose is dissolved in a non-derivatizing solvent such as $\mathrm{N}$, N-dimethylacetamide/lithium chloride or dimethylsulfoxide/tetrabutylammonium. This solution will break the molecular bond of the cellulosic hydrogen complex and increase the accessibility of the hydroxyl group to readily react with other compounds. This modification is difficult in hardwood fibers because of its more complex molecular structure. But this method can be done on OPEFB fiber or agro-industry wastes because it has a shorter fiber size with low density. The weakness of homogeneous way is the need for large solvent volume ratio to dissolve cellulose and if the solution system is not correct will cause the hydrogen bond to break unevenly. The advantage of this method is that the degree of substitution can be adjusted, taking place at low temperatures $\left(<70^{\circ} \mathrm{C}\right)$ and not at risk of damaging the cellulosic polymer backbone (Vaca-Garcia et al., 1998).

The heterogeneous modification is performed by mixing surfactant, dilute acid, sulfonyl chloride or carboxylic acid. This method is very complicated, it is difficult to determine which compounds are most influential on the breakdown of cellulosic hydrogen molecules, requiring high temperatures and long duration and risk of breaking the main polymer bond (Crepy et al., 2009). Huang et al. (2012) also reported heterogeneous cellulosic modification processes performed using a combination of ball mill techniques and an alkaline catalyst to break the cellulosic hydrogen bonds.

The modified cellulose will readily react with the alkyl donor ester such as fatty acid chloride or acetic acid to produce bio-plastic. In addition, the use of fatty acid chloride is more desirable than the use of acetic acid as a reagent in the manufacture of bio-plastics. This is because the fatty acid chloride has a longer carbon chain (Ratanakamnuan et al., 2013).

Some research on biodegradable plastic technology has been done. The publication of the effect of fatty acid chain length on the cellulosic ester's thermo-mechanical properties has been reported by Crepy et al. (2011). According to them, the use of fatty acids having more than 12 carbon chains will cause the alkyl chain to be hexagonal crystals and have an effect on mechanical properties. It is also reported by Chauvelon et al. (2000) that long chain cellulose esters have better thermal stability than short chain ester cellulose.

The cellulosic alkylation reaction was carried out by Heinze et al. (2003). Then, Huang (2011) synthesized the cellulose stearate biopolymer by reacting the cellulose with trifluoroacetic anhydride and stearic acid. Characteristics of cellulose oleate has also been reported by Huang et al. (2011). Some literatures stated that the use of fatty acid chloride with a high carbon chain amount will reduce the molar ratio of the reagents and improve the mechanical properties of bio-plastics.

Several types of fiber have been converted into bio-plastics. Joly et al. (2005) performed acetylation of cellulose from sawdust with fatty acid chloride in a solution of dimethyl aminopyrridine. Zhang et al. (2013) performed esterification of eucalyptus cellulose with palmitoil chloride. Ciacco et al. (2003) reacted sisal cellulose with fatty acids in a solution of dimethyl solfoxida/tetra butyl ammonium. El Seoud et al. (2000) also carried out cellulose esterification of cane waste by means of homogeneous modification. Freire et al. (2008) have reported the manufacture of composites from a mixture of bio-plastic and LDPE. Composite products have better mechanical properties and increased water resistance. Both properties are obtained from the degree of substitution and the length of the fatty acid carbon chain used.

One of the agro-industry wastes that can be used as a natural polymer source is OPEFB. OPEFB is a continuous ligno-cellulosic waste produced by Palm Oil Mill (POM) in huge amount as well as palm oil. In some POM, OPEFB did not utilize well, and it becomes a problem for the environment. Herawan and Rivani (2015) have published a synthesis of biodegradable plastic by esterification of oil palm empty fruit bunch cellulose with several commercial alkyl chlorides. Nevertheless, the bio-plastic film still has lower tensile strength than a commercial plastic bag that is $30-30$ $\mathrm{kg} . \mathrm{f} / \mathrm{cm}^{2}$.

This paper will report about utilization of OPEFB as a raw material for preparation of cellulose ester by esterification of cellulose of OPEFB and modified palm oil based fatty acid to improve some physical and chemical properties of its products. 


\section{MATERIALS AND METHODS Materials}

The main materials used in this study were oil palm empty fruit bunches (OPEFB) obtained from the Palm Oil Mill (POM) Adolina PT Perkebunan Nusantara IV, palm fatty acids from local distributors, while thionyl chloride, $\mathrm{N}$ dimethylacetamide, lithium chloride, and other chemicals used in this experiment are supplied from PT Merck.

\section{Methods \\ Cellulose production}

A number of dry OPEFB were introduced into a tank containing $4 \% \mathrm{KOH}$ solution then heated for two hours at $100^{\circ} \mathrm{C}$. Thereafter, the residue was immersed in $2.5 \%$ sodium hypochlorite for 24 hours at room temperature. Cellulose OPEFB was filtered, washed to neutral and dried. Then, dry OPEFB cellulose was immersed in a $17.5 \% \mathrm{NaOH}$ solution for an hour and then filtered. The residue was washed with $8.3 \% \mathrm{NaOH}$ and washed with aqua distillated and dried. Cellulose product was analyzed according to SNI 14-0492-1990A for lignin composition, SNI 14-1303-1989A for holocellulose compositions, and SNI 14-0444-1989A for $\alpha$-cellulose compositions.

\section{Preparation of fatty acid chloride based on oil palm fatty acid}

A number of oil palm based fatty acids which contain a high amount of palmitic acid or lauric acid was mixed in thionyl solution with a weight ratio of 1:25. Then, about $10 \%$ dimethylformamide was added to the same reactor and heated for 2 hours at $65^{\circ} \mathrm{C}$. The product of fatty acid chloride was then characterized using gas chromatography, and used as alkyl donor for cellulose esters production.

\section{Cellulose esters production}

A number of $\alpha$-cellulose of OPEFB was introduced into a reactor containing a $0.7 \% \mathrm{~N}$ dimethylacetamide/lithium chloride solution. This mixture was stirred and heated for 3 hours at $110^{\circ} \mathrm{C}$. Then the temperature was lowered to $80^{\circ} \mathrm{C}$ before added modified palm fatty acid with certain types (lauryl chloride or palmitoyl chloride) and the various ratio of $\alpha$ - cellulose/alkyl chloride $(1 / 5,1 / 6,1 / 7,1 / 8$ $\mathrm{mol} / \mathrm{mol}$ ). Esterification lasted for five hours with reflux and stirring. Cellulose ester product was purified with ethanol then extracted with ethanol solvent for 6 hours. The purified product was dried.

A number of \pm 0.7 grams of a purified cellulose ester product were dissolved in $15 \mathrm{ml}$ of chloroform and then printed on a glass plate. The chloroform was then evaporated. Bio-plastic sheet products will be obtained and analyzed its physical and chemical properties.

\section{Bio-plastic analysis and characterization}

The chemical structure and identification of cellulose ester were analyzed by Fourier Transform Infrared Spectroscopy (Alpha FTIR Spectrometer Bruker Optik GmbH).

The thermal cellulose ester testing was performed in accordance with ASTM D 3418 procedure using Differential Scanning Calorimeter tool (DSC 800 Perkin Elmer) to determine glass transition temperature, melting point and enthalpy. The solubility of cellulose ester was tested with chloroform solvent,

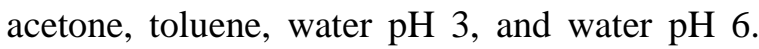
While cell surface morphology testing of cellulose and its derivate was done by SEM (Scanning Electron Microscopy/JEOL JSM6510 LA SEM-EDS) and the tensile strength of the bio-plastic film was also analyzed by Universal Testing Machine Instron Al700.

\section{RESULTS AND DISCUSSION}

\section{Characteristic of cellulose produced from OPEFB}

In general, woody plants including OPEFB consist of cellulose and hemi-cellulose polymer bonds attached by lignin. The magnitude of the composition of cellulose, hemi-cellulose and lignin in OPEFB was almost the same despite the largest cellulose composition among others (Table 1). The process of cellulose isolation of OPEFB affects its chemical composition. The addition of alkaline and sodium hypochlorite solution not only removes $93-98 \%$ lignin from micro-fibrils but also reduces about $77-100 \%$ silica and 36-89\% extractive in OPEFB fibers. 
Table 1. The chemical composition of OPEFB and its fraction.

\begin{tabular}{clccc}
\hline No. & \multicolumn{1}{c}{ Composition } & OPEFB $(\%)$ & Cellulose $(\%)$ & $\alpha$-Cellulose $(\%)$ \\
\hline 1. & Ash & 6.23 & 0.51 & 0.40 \\
2. & Silica & 1.10 & 0.25 & 0 \\
3. & Lignin & 20.62 & 1.13 & 0.41 \\
4. & Extractive & 7.78 & 5.00 & 1.03 \\
5. & Holo-Cellulosa & 66.07 & 93.50 & 98.85 \\
& - $\alpha$-Cellulose & 37.50 & 64.75 & 90.90 \\
& - Hemi- Cellulose & 28.43 & 28.75 & 7.15 \\
6. & Rendemen $(\%$ dried & - & $40-47$ & $32-38$ \\
\hline
\end{tabular}

This is also evidence from the SEM, image of Figure 1a shows that there is still a lignin and extractive layer (rough surface) covering the cellulose micro-fibrils and there is silica (white spheres on the micro-fibril surface). After the process, as shown in Figure $1 \mathrm{~b}$, the lignin, extractive and silica layers are not or are slightly visible. The surface of the cellulose fibrils is smoother although still bonded (Herawan et al., 2013).

The SEM analysis results show that the micro-fibril size changes from 180-200 $\mu \mathrm{m}$ (OPEFB) to 20-190 $\mu \mathrm{m}$ (Figure 1). XRD results can be seen in Figure 2, where CrI increased from $52.83 \%$ (OPEFB dry count) to 59.16$61.21 \%$ (Cellulose OPEFB).

The $\alpha$-cellulose of OPEFB is obtained from OPEFB cellulose soak in high concentrated alkali. In Table 1 , it can be seen that this immersion process removes most of the hemicellulose $(20-35 \%)$ so that the $\alpha$-cellulose composition increases from its initial composition in OPEFB cellulose.
Visually, $\alpha$-cellulose looks smoother than cellulose OPEFB (Figure 3a). This is shown from the smaller micro fibrils diameter of 11-16 $\mu \mathrm{m}$ (Figure $3 \mathrm{~b}$ ). CrI alpha cellulose is also much higher than CrI cellulose TKS i.e. 68.39-73.05\% (Figure 3c). Some of these results prove that there is an effect of the alkali concentration on the immersion process on the quality of alpha cellulose products.

\section{Cellulose Esters Production}

The modified fatty acid product (fatty acid chloride) was esterified with $\alpha$-cellulose OPEFB to produce cellulose ester. The $\alpha$-cellulose was dissolved in a solution of dimetylacetamide $/ \mathrm{LiCl}$ $(6.75 \%)$. The solution used was a non-derivative solvent that solely for dissolving $\alpha$-cellulosic and does not cause it to be degraded. This process takes place in a homogeneous way. The soluble $\alpha$-cellulose was then reacted with a number of fatty alkyl chloride in various molar ratio. In general, cellulose esterification was performed by adding more than five times molar ratio of fatty acid chloride.

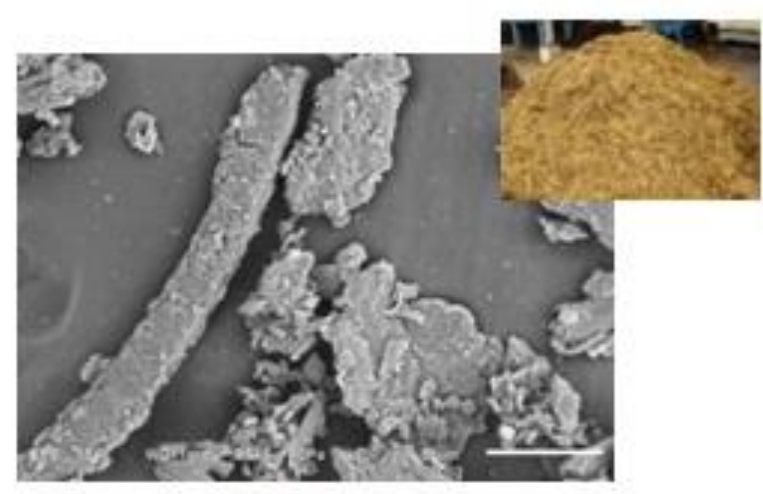

(a)

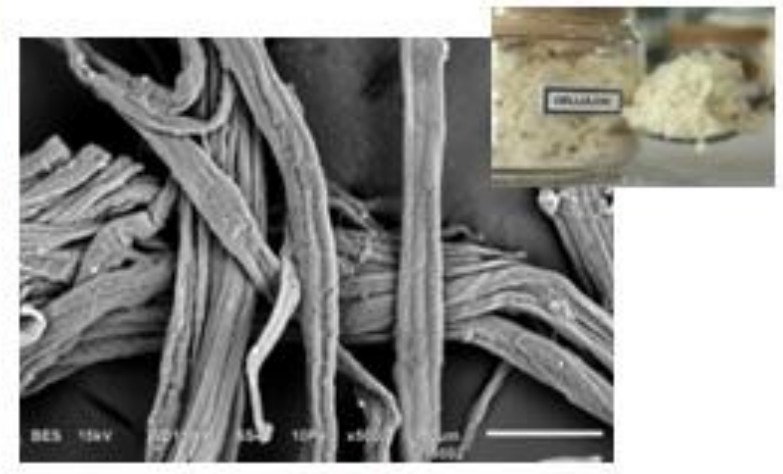

(b)

Figure 1. Results of morphological analysis with SEM (a) OPEFB; (b) cellulose 


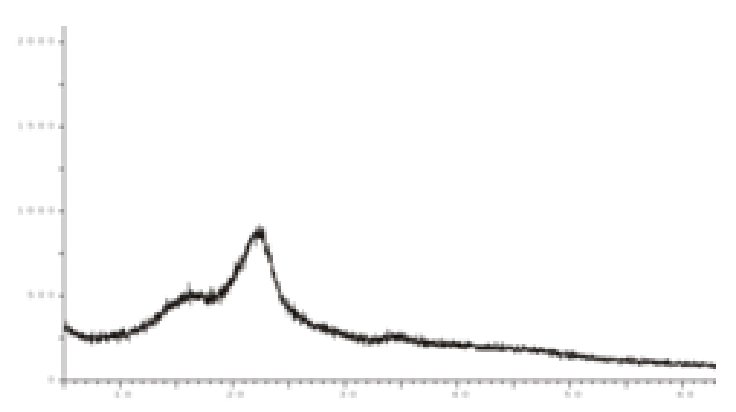

(a)

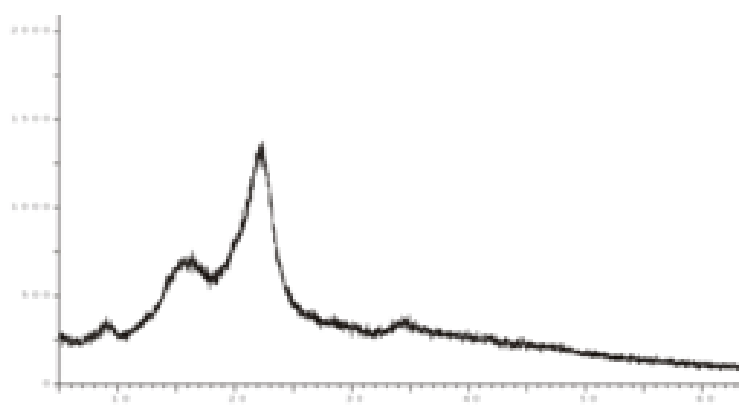

(b)

Figure 2. CrI results with XRD (a) OPEFB; (b) cellulose of OPEFB

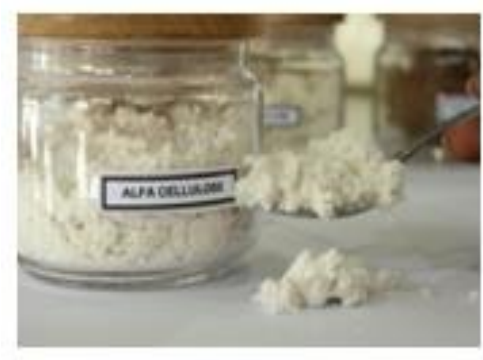

(a)

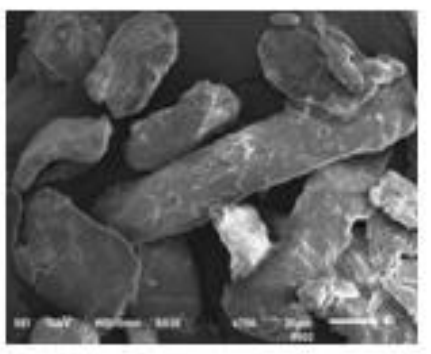

(b)

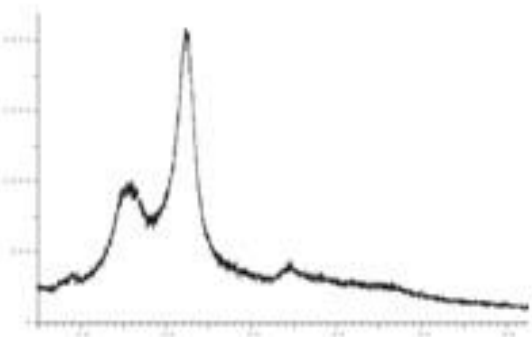

(c)

Figure 3. $\alpha$-cellulose from OPEFB (a) Visual; (b) SEM morphology; (c) CrI of XRD

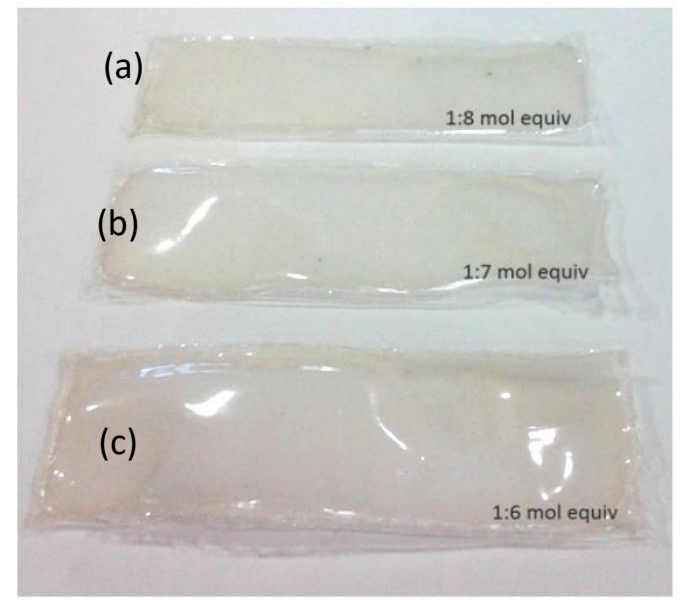

Figure 4. Bioplastic products of cellulose OPEFB and fatty acid chloride (a). Cellulose OPEFB + Palmitoil chloride pa, (b). Cellulose OPEFB + modified palmitic acid (c). Cellulose OPEFB + modified lauric acid.

The result of the synthesis of cellulose ester bio-plastic from OPEFB and fatty acid chloride can be seen in Figure 4.

The FTIR analysis is used to look at the changes in the chemical structure of a compound. There are three important functional groups of a characteristic of the bio-plastic product, namely hydroxyl $(\mathrm{OH})$, ester $(\mathrm{C}=\mathrm{O})$ and $\mathrm{C}-\mathrm{H}$. In Figure 5 it can be seen that the absorbance decrease at hydroxyl wave length $3500-3400 \mathrm{~cm}^{-1}$ from alpha cellulose raw material to cellulose ester product. This indicates that the hydroxyl group in the product has been substituted with the fatty acid group palmitoil, lauroyl, etc. On the other hand, the absorbance of the ester in 1750-1700 $\mathrm{cm}^{-1}$ appears in the cellulose ester product whereas the ester spectra do not appear in the $\alpha$-cellulose feedstock. The ester absorbency increases with the use of longchain fatty acids chloride.

This method also shows that there is more than $500 \%$ increase in product weight for the manufacture of cellulose laurate and $469 \%$ in the manufacture of cellulose palmitate, each with a degree of substitution (DS) of 2.35 and 2.27. The melting point of cellulose laurate is $224^{\circ} \mathrm{C}$, whereas cellulose palmitate is $201{ }^{\circ} \mathrm{C}$. This shows that there is a chemical change of cellulose structure which naturally has no melting point. Thus, the modification of cellulose into long chain cellulose esters would greatly facilitates its application as a packaging 
product or other consumable product because the value of the melting point is close to a melting point of commercial plastics ranging from 100$180^{\circ} \mathrm{C}$.

Without the addition of any additives, the cellulose ester also has a good tensile strength. The tensile strength of cellulose laurate was $71.69 \mathrm{~kg} . \mathrm{f} / \mathrm{cm}^{2}$, while the tensile strength of cellulose palmitate was $73.73 \mathrm{~kg} . \mathrm{f} / \mathrm{cm}^{2}$, slightly lower than the tensile strength of commercial plastics of LDPE used as a comparison of 108 $\mathrm{kg} . \mathrm{f} / \mathrm{cm}^{2}$.

Solubility test also shows that cellulose ester bio-plastic is well soluble in chloroform and toluene, but is insoluble in water with either acidic or hot water levels. Cellulose ester bioplastics are also insoluble in esters, oils and alcohols. Thus, cellulose ester bio-plastics are best used as an oil-resistant waterproof packaging material as well as alcohol.

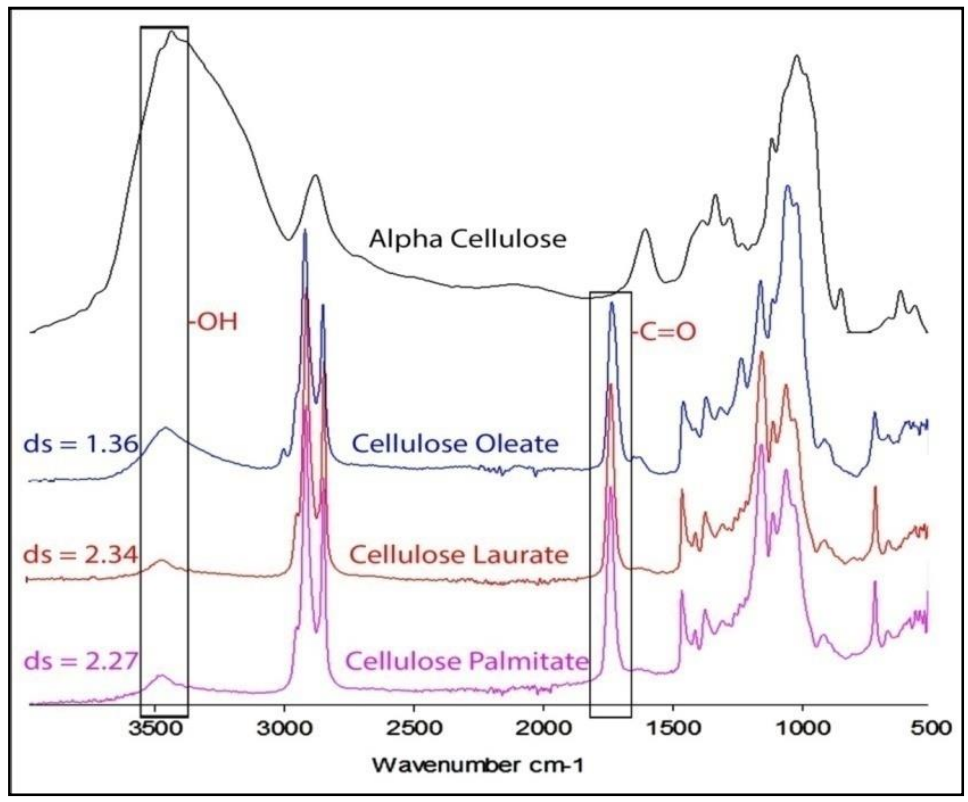

Figure 5. FTIR characteristics of bio-plastic products

\section{CONCLUSION}

Cellulose ester was successfully synthesized through esterification of empty palm fruit bunches and palm oil fatty acids that have been modified under moderate conditions. The cellulose ester bio-plastics which was produced from derivate palm fatty acid and cellulose of oil palm empty fruit bunch have lower tensile strength compare to the petroleum-based plastics commercial (LDPE) of $73 \mathrm{~kg} / \mathrm{cm}^{2}$ (cellulose palmitate) and $71.69 \mathrm{~kg} / \mathrm{cm}^{2}$ (cellulose laurate) versus $108 \mathrm{~kg} / \mathrm{cm}^{2}$ (LDPE plastic). The addition of additive are needed to increase tensile strength and its elasticity properties.

\section{ACKNOWLEDGEMENT}

The authors are grateful to the financial support given by Badan Pengelola Dana Perkebunan Kelapa Sawit (BPDP-KS), Ministry of Finance, Indonesia through Oil Palm Research Grant 2015-2016.

\section{REFERENCES}

Freire, C. S. R., Silvestre, A. J. D., Neto, C. P., Gandini, A., Martin, L., \& Mondragon, I. (2008). Composites based on acylated cellulose fibers and low-density polyethylene: Effect of the fiber content, degree of substitution and fatty acid chain length on final properties. Composites Science and Technology, 68(15-16), 3358-3364. https://doi.org/10.1016/j.compscitech.2008.09.00 $\underline{8}$

Chauvelon, G., Gergaud, N., Saulnier, L., Lourdin, D., Buleon, A., Thibault, J. F., \& Krausz, P. (2000). Esterification of cellulose-enriched agricultural by-products and characterization of mechanical properties of cellulosic films. Carbohydrate Polymers, 42(4), 385-392. https://doi.org/10.1016/S0144-8617(99)00187-3

Ciacco, G. T., Liebert, T. F., Frollini, E., \& Heinze, T. J. (2003). Application of the solvent dimethyl sulfoxide/tetrabutyl-ammonium flouride trihydrate as reaction medium for the homogeneous acylation of Sisal cellulose. Cellulose, 10(2), 125-132. https://doi.org/10.1023/A:1024064018664 
Crepy, L., Chaveriat, L., Banoub, J., Martin, P., \& Joly, N. (2009). Synthesis of cellulose fatty esters as plastics - Influence of the degree of substitution and the fatty chain length on mechanical properties. ChemSusChem: Chemistry \& Sustainability Energy \& Materials, 2(2), 165-170. https://doi.org/10.1002/cssc.200800171

Crepy, L., Miri, V., Joly, N., Martin, P., \& Lefebvre, J. (2011). Effect of side chain length on structure and thermomechanical properties of fully substituted cellulose fatty esters. Carbohydrate Polymers, 83(21), 1812-1820. https://doi.org/10.1016/j.carbpol.2010.10.045

El Seoud, O. A., Regiani, A., \& Frollini, E. (2000). Derivatization of cellulose in homogeneous conditions. A brief review. In: Frollini E., Leão A.L. and Mattoso L.H.C. (eds). Natural Polymers and Agrofibers Composites, São Carlos, Brazil, 73-90.

Hairani, N., Harahap, H., Herawan, T., \& Taslim. (2015). The effect of glycerol and oil palm empty fruit bunches microcrystalline cellulose loading on tensile properties and water absorption of cassava starch composite. Advanced Materials Research, 1123 ,

151-154. https://doi.org/10.4028/www.scientific.net/AMR. 1123.151

Heinze, T., Liebert, T. F., Pfeiffer, K. S., \& Hussain, M. A. (2003). Unconventional cellulose esters: Synthesis, characterization and structureproperty relations. Cellulose, 10(3), 283-296. https://doi.org/10.1023/A:1025117327970

Herawan, T., \& Rivani, M. (2015). Synthesis of biodegradable plastic films from oil palm empty fruit bunch cellulose. Advanced Materials Research, 1123, 173-176. https://doi.org/10.4028/www.scientific.net/AMR. $\underline{1123.173}$

Herawan, T, Rivani, M., Sinaga, K., \& Sofwan, A. G. (2013). Pembuatan mikrokristal selulosa tandan kosong sawit sebagai bahan baku pengisi tablet karoten sawit. Prosiding Seminar Insentif Riset SINas, 137-147.

Huang, F. Y. (2011). Synthesis and properties of cellulose stearate. Advanced Materials Research, 228-229, 919-924. https://doi.org/10.4028/www.scientific.net/AMR. $\underline{228-229.919}$
Huang, F. Y., Yu, Y., \& Wu, X. J. (2011). Characterization and properties of cellulose oleate. Advanced Materials Research, 197-198, 1306-1309.

https://doi.org/10.4028/www.scientific.net/AMR. $\underline{197-198.1306}$

Huang, Z., Tan Y., Zhang, Y., Liu X., Hu, H., Qin, Y., \& Huang, H. (2012). Direct production of cellulose laurate by mechanical activationstrengthened solid phase synthesis. Bioresource Technology, 118, 624-627. https://doi.org/10.1016/j.biortech.2012.05.082

Isroi, Cifriadi, A., Panji, T., Wibowo, N. A., \& Syamsu, K. (2017). Bioplastic production from cellulose of oil palm empty fruit bunch. IOP Conference Series: Earth and Environmental Science, $\quad$ 65(1), 1755-1315. https://doi.org/10.1088/1755-1315/65/1/012011

Joly, N., Granet, R., Branland, P., Verneuil, B., \& Krausz, P. (2005). New methods for acylation of pure and sawdust-extracted cellulose by fatty acid derivatives - Thermal and mechanical analyses of cellulose-based plastic film. Journal of Applied Polymer Science, 97(3), 1266-1278. https://doi.org/10.1002/app.21783

Ratanakamnuan, U., Manorom, W., \& Inthasai, P. (2013). Preparation of biodegradable film from esterified corn husk cellulose. Advanced Materials Research, 701, 229-233. https://doi.org/10.4028/www.scientific.net/AMR. $\underline{701.229}$

Vaca-Garcia, C., Thiebaud, S., Borredon, M. E., \& Gozzelino, G. (1998). Cellulose esterification with fatty acids and acetic anhydride in lithium chloride/N,N-dimethylacetamide medium. Journal of American Oil Chemists' Society, 75(2), 315-319. https://doi.org/10.1007/s11746998-0047-2

Zhang, A., Mei, L., Zhao, Z., Xie, J., Liu, C., \& Sun, R. (2013). Homogeneous esterification of eucalyptus with palmitoyl chloride at room temperature. BioResources, 8(3), 4288-4297. https://doi.org/10.15376/biores.8.3.4288-4297 
